\title{
AS FUNÇÔES DO PARATEXTO PARA A INTELIGIBILIDADE DA OBRA TRADUZIDA
}

\section{Patrizia Collina Bastianetto*}

RESUMO: Este estudo pretende analisar as funções do paratexto e sua importância para a inteligibilidade da obra traduzida. Com efeito, os fragmentos verbais que contornam o texto, isto é, o paratexto, podem assumir um papel significativo para a compreensão textual e a orientação argumentativa. Nesse sentido, é também objetivo deste estudo ilustrar em que medida as diferenças paratextuais presentes em várias edições da mesma obra traduzida podem incidir na legibilidade. A abordagem teórica para as referidas reflexões recorre à Teoria do Texto, à Teoria da Tradução e à Teoria da Recepção e Leitura. As observações resultam da análise de sete traduções para a língua portuguesa do tratado de direito penal Dos Delitos e das Penas de Cesare Beccaria, autor italiano do século XVIII.

UNITERMOS: tradução; paratexto; inteligibilidade; argumentação.

ABSTRACT: This paper intends to analyze the functions of the paratext and its importance for the comprehension of translated texts. The verbal fragments that surround a text, i.e. the paratext, can actually have a significant role in text comprehension and in argumentative orientation. It is also our objective to illustrate the extent to which paratextual differences found in various editions of the same translated work can affect its legibility. The theoretical approach for these reflections is based on the Theory of Text, the Theory of Translation, and on the Theory of Reception and Reading. The observations come from the analysis of seven

* Faculdade de Letras da UFMG. 
Portuguese translations of the work Dei Delitti e Delle Pene, a treatise on penal law written by Cesare Beccaria, an Italian author of the 18th century.

KEYWORDS: translation; paratext; legibility; argumentation.

Este artigo se origina de uma pesquisa acadêmica concluída em 2004 sobre legibilidade e argumentação em textos traduzidos. Naquele estudo, analisamos os fatores constituintes da legibilidade e da argumentação em referidos tipos de texto e, aqui, retomamos o tema dando ênfase ao paratexto. O objetivo é mostrar, neste trabalho, a multiplicidade de funções do paratexto e sua importância para a inteligibilidade dos textos traduzidos.

As observações deste trabalho, com relação aos elementos paratextuais do texto traduzido, originam-se do exame do tratado Dos delitos e das penas, do jurista Cesare Beccaria. A primeira edição do texto foi publicada em 1764, anônima e sem data. Nessa época, justamente, o território que, em 1860, se tornaria a nação italiana, estava dividido em onze estados e a cidade de Milão, onde o autor vivia, encontrava-se sob o pesado domínio austriaco.

O livro original é escrito em italiano e conta com sete edições para o português do Brasil, duas delas assinadas pelo mesmo tradutor. Apesar disso, uma análise revela diferenças textuais e paratextuais entre essas duas edições: com relação ao texto, as diferenças residem no emprego de elementos qualificadores ou de modalização de orações; quanto ao paratexto, as diferenças se constatam no que diz respeito, por exemplo, às notas de rodapé. E esse fato faz com que, neste estudo, se considerem diferentes as duas edições acima referidas, apesar de o tradutor ter sido o mesmo.

A existência de sete edições traduzidas da mesma obra oferece uma boa oportunidade de análise que, como anunciado, estará, aqui, centrada no paratexto.

O paratexto é definido por Maingueneau (2001, p. 81) como um "conjunto de fragmentos verbais que acompanham o texto propriamente dito". Explicitando, esses fragmentos verbais são 
constituídos pelo título, subtítulo, prefácio, posfácio, encartes, sumário, etc.

No dicionário de Termos-chave da análise do discurso, Maingueneau (2000) distingue o "paratexto autoral" do "paratexto editorial". O primeiro contém textos produzidos pelo autor, isto é, título, epígrafe, prefácio, dedicatória, notas de rodapé, etc. O segundo, são dados produzidos pelo editor, tais como textos figurando na capa ou na orelha da obra, informações da ficha catalográfica, indice e copyright, dentre outros.

Aqui nos propomos estudar aspectos de ambos os tipos de paratexto. Do paratexto editorial, serão avaliados dados constantes da ficha catalográfica, a presença ou não de ilustrações e as notas de rodapé, incluindo as notas do tradutor. Do paratexto autoral serão tratadas a epígrafe e as notas de rodapé.

Cabe observar que o leitor de um texto traduzido não costuma ter acesso a diversas traduções da mesma obra e, mesmo o tendo, dificilmente compraria mais de um volume do mesmo título, apenas pelo fato de ter sido traduzido e publicado por tradutores e editoras diferentes - a não ser em situações específicas, como no caso em que queira realizar uma pesquisa.

Os elementos paratextuais são significativos para uma boa inteligibilidade, pois eles têm relevância na constituição do significado. De fato, neles residem pistas de leitura que geram predições e expectativas. Quando essas pistas não levam ao caminho apontado e esperado, há certa dificuldade de compreensão. Nesse caso específico, a dificuldade não decorre de problemas lingüísticos stricto sensu, mas dos elementos paratextuais.

Com relação à legibilidade, faremos aqui uma digressão para explicitar como ela é concebida. Lembramos que a compreensão de textos é um processo complexo em que interagem diversos fatores, tais como os conhecimentos lingüísticos, o conhecimento prévio do assunto tratado, o conhecimento geral a respeito do mundo, a motivação e o interesse na leitura. Além desses fatores, presentes na mente do leitor, há ainda o aspecto visual do texto, relativo aos elementos inscritos na superficie do papel (ou de qualquer outro material que veicula o texto). Esses fatores, visuais e não-visuais, atuam na leitura e são fundamentais para a compreensão textual. 
Com efeito, Fulgêncio e Liberato (2000, p. 96) definem legibilidade como "uma interação entre o leitor e o texto ou, mais especificamente, entre o conhecimento prévio do leitor e a informação que ele capta do texto". Ou seja, a legibilidade relacionase à inteligibilidade, à compreensibilidade do texto e remete ao fato de o leitor conseguir ou não entender as informações transmitidas pelo autor, e com que grau de dificuldade.

A significação requer, portanto, uma associação íntima entre o modo como o texto é construído e a organização da mente do leitor. Logo, um texto pode ser legivel para uma pessoa e ilegivel para outra.

Com relação à análise proposta, apresentamos, por meio de tabelas, o paratexto das sete edições brasileiras da obra Dos delitos e das penas e das edições italianas que o originaram. Na primeira tabela, são apresentados os dados catalográficos, portanto, o paratexto editorial. Da segunda tabela, constam os dados referentes às notas de rodapé, que incluem, também, o paratexto autoral. Já na terceira tabela, são tratados outros aspectos do paratexto, tais como a presença da ilustração e da tradução da epígrafe nos textos traduzidos. 
Tabela 1

Dados catalográficos de sete versões brasileiras de Dos Delitos e das Penas, Cesare Beccaria e das edições do texto da língua do original.

\begin{tabular}{|c|c|c|c|c|}
\hline $\begin{array}{c}\text { Editora } \\
\text { Nome e Local }\end{array}$ & $\begin{array}{l}\text { Dados da edição } \\
\text { do texto da língua } \\
\text { de tradução }\end{array}$ & $\begin{array}{l}\text { Dados da edição } \\
\text { do texto da língua } \\
\text { do original }\end{array}$ & Tradutor(es) & $\begin{array}{l}\text { Tipo de coleção } \\
\text { nas duas edições }\end{array}$ \\
\hline $\begin{array}{l}\text { 1. Revista dos } \\
\text { Tribunais/São Paulo }\end{array}$ & $\begin{array}{c}\text { 1999, } 2^{\mathrm{a}} \text { tiragem da } \\
2^{\mathrm{a}} \text {. edição revista, } \\
\text { em } 47 \text { capítulos }\end{array}$ & $\begin{array}{l}\text { Editrice UTET: } \\
\text { Torino, } 1911\end{array}$ & $\begin{array}{l}\text { J. Cretella Jr. e } \\
\text { Agnes Cretella }\end{array}$ & $\begin{array}{c}\text { Texto da LT* } \\
\text { Textos } \\
\text { Fundamentais } \\
\text { Texto da LO** } \\
\quad \ldots\end{array}$ \\
\hline 2. CD/São Paulo & $\begin{array}{l}2001,1^{\mathrm{a}} \\
\text { reimpressão da } 1^{\mathrm{a}} \\
\text { edição de } 2000, \text { em } \\
42 \text { capítulos }\end{array}$ & $\begin{array}{c}\text { Giuffrè: Milano, } \\
1946\end{array}$ & $\begin{array}{l}\text { Vicente Sabino } \\
\text { Jr. }\end{array}$ & $\begin{array}{c}\text { Texto da LT } \\
- \\
\text { LO } \\
\text { Civiltà del diritto }\end{array}$ \\
\hline 3. Hemus/Curitiba & $\begin{array}{c}2000,5^{\mathrm{a}} \\
\text { reimpressão da } 11^{\mathrm{a}} \\
\text { edição, em } \\
42 \text { capítulos }\end{array}$ & - & $\begin{array}{c}\text { Torrieri } \\
\text { Guimarães }\end{array}$ & $\begin{array}{c}\text { Texto da LT } \\
\text { Ciências Sociais } \\
\text { \& Filosofia } \\
\text { LO }\end{array}$ \\
\hline 4. Edipro/São Paulo & $\begin{array}{l}2001,6^{\mathrm{a}} \\
\text { reimpressão da } 1^{\mathrm{a}} \\
\text { edição de } 1993, \text { em } \\
42 \text { capítulos }\end{array}$ & - & $\begin{array}{c}\text { Flório de Angelis } \\
\text { revisão: F. Pais e } \\
\text { F. Flório }\end{array}$ & $\begin{array}{l}\text { Texto da LT } \\
\text { Clássicos } \\
\text { LO }\end{array}$ \\
\hline $\begin{array}{l}\text { 5. Martin Claret/São } \\
\text { Paulo }\end{array}$ & $\begin{array}{l}\text { 2002, em } 42 \\
\text { capítulos }\end{array}$ & $\begin{array}{c}\text { "Texto integral" } \\
\text { Fonte: não } \\
\text { informada }\end{array}$ & $\begin{array}{c}\text { Torrieri } \\
\text { Guimarães }\end{array}$ & $\begin{array}{c}\text { Texto da LT } \\
\text { A obra-prima de } \\
\text { cada autor } \\
\text { LO }\end{array}$ \\
\hline $\begin{array}{l}\text { 6. Martins Fontes/São } \\
\text { Paulo }\end{array}$ & $\begin{array}{l}2002,6^{\mathrm{a}} \text { tiragem da } \\
2^{\mathrm{a}} \text {. edição de } 1996 \\
\text { em } 47 \text { capítulos }\end{array}$ & - & $\begin{array}{l}\text { L. Guidicini e } \\
\text { Berti Contessa } \\
\text { revisão: R. L. } \\
\text { Ferreira }\end{array}$ & $\begin{array}{c}\text { Texto da LT } \\
\text { Clássicos } \\
\text { Ciências Sociais } \\
\text { Texto da LO } \\
\text { Classici }\end{array}$ \\
\hline 7. WVC/São Paulo & $\begin{array}{l}\text { 2002, em } 47 \\
\text { capítulos }\end{array}$ & - & $\begin{array}{l}\text { J. R. Malta } \\
\text { revisão: M. } \\
\text { Pugliesi }\end{array}$ & $\begin{array}{l}\text { Texto da LT } \\
\text { Filosofia } \\
\text { Direito } \\
\text { LO } \\
\text { _ }\end{array}$ \\
\hline
\end{tabular}

* LT = Lingua de Tradução

** LO = Lingua de Origem 


\section{Dos dados catalográficos}

Na primeira coluna da tabela acima, encontram-se os dados referentes à quantidade de edições publicadas, a data da primeira edição e das sucessivas reimpressões e revisões. Com relação a essa informação, as sete edições fornecem os dados completos.

O conhecimento desses dados representa um subsídio para a pesquisa relacionada à tradução. Ter conhecimento da data de publicação da primeira edição de uma obra traduzida significa saber quando a tradução foi feita. A partir disso, é possível tecer as implicações decorrentes de variáveis que podem ter tido alguma incidência sobre aquele texto traduzido. Faz-se referência, por exemplo, à variável ligada a elementos extralingüísticos, isto é, à situação enunciativa do país de recepção, como, por exemplo, um regime de governo autoritário, a guerra fria, etc. No caso do aparecimento da obra Dos delitos e das penas no Brasil, se sua primeira edição foi realmente em 1837 pela Editora Athena do Rio de Janeiro, assim como uma pesquisa em diversas bibliotecas brasileiras apontou - portanto anterior ao decreto de abolição da pena de morte, promulgado na primeira Constituição Republicana -, não seria descartável a hipótese de que o editor tenha sido submetido a algum tipo de censura a qual tenha lhe condicionado certas escolhas tradutórias. Esclarecemos, pois, que no tratado o autor condena os hábitos então vigentes da tortura e da pena de morte.

Uma outra variável que pode interferir no texto traduzido é a temporal. Como se sabe, as revoluções ideológicas refletemse em muitos aspectos da vida e, inclusive, na abordagem tradutória. Sendo assim, épocas diferentes sugerem posturas tradutórias também diferentes, cada qual espelhando a visão de mundo vigente no momento em que a tradução é realizada.

Pelos mesmos motivos, quem se propõe fazer uma análise do produto tradutório, precisa saber se a editora, ao se dedicar às reimpressões da obra, promoveu revisões que originaram alterações textuais e em que data.

$\mathrm{Na}$ ficha catalográfica do texto traduzido, a presença das referências editoriais completas do livro estrangeiro é substan- 
cial para o pesquisador que quer comparar o texto de chegada com o texto de partida.

A Tabela 1 mostrou que, das sete edições brasileiras da obra beccariana, apenas duas informam, na ficha catalográfica, os dados da edição italiana em que a tradução se baseou.

Faz-se necessário sublinhar que a falta dessas referências não afeta apenas o pesquisador, mas o leitor comum também. Este fica privado de conhecer a situação enunciativa do livro fonte, caso queira contextualizar melhor a obra, estando impedido de buscar, em seu conhecimento enciclopédico, as informações necessárias para uma compreensão mais abrangente da obra traduzida.

Continuando a leitura da Tabela 1 , verifica-se que as diversas edições não têm o mesmo número de capítulos. De fato, três edições traduzidas são constituídas de 47 capítulos e 4 edições de 42 capítulos. Tendo em vista as diversas alterações que a obra recebeu pela mão do autor, é importante ressaltar que a edição de 1766 é aquela cujo texto foi considerado, pelo próprio autor, como o definitivamente estabelecido, sendo, portanto, a edição clássica ou autorizada.

Com relação à explicitação do nome dos tradutores, sempre na Tabela 1, na ficha catalográfica das sete traduções, não há problemas: todos os nomes foram anunciados.

Outra consideração é salutar com relação a essa Tabela. Na última coluna à direita, é possível verificar que, das sete edições traduzidas, seis catalogam a obra dentro de uma série específica. Observa-se que esse dado também cria expectativas de leitura e orienta o público com relação ao tipo de texto que o espera.

Concluindo a leitura da Tabela 1, acredita-se que essas poucas observações, com relação à ficha catalográfica das obras traduzidas, bastem para atestar o grande número de informações que a mesma pode encerrar; bastam, ainda, para confirmar o quanto isso pode incidir no grau de legibilidade do texto traduzido.

Apresentamos, a seguir, a Tabela 2, que ilustra o tratamento dado às notas de rodapé pelas sete versões brasileiras da obra de Beccaria. 


\section{Tabela 2}

Notas de rodapé no paratexto autoral e editorial Dos Delitos e das Penas, Cesare Beccaria.

\begin{tabular}{|c|c|c|c|}
\hline $\begin{array}{c}\text { Editora do texto da Língua } \\
\text { de tradução }\end{array}$ & $\begin{array}{l}\text { Notas de rodapé do } \\
\text { texto da Língua de } \\
\text { tradução }\end{array}$ & $\begin{array}{l}\text { Editora do texto da } \\
\text { Língua de origem }\end{array}$ & $\begin{array}{c}\text { Notas de rodapé do } \\
\text { texto da Língua de } \\
\text { origem }\end{array}$ \\
\hline $\begin{array}{l}\text { 1. REVISTA DOS } \\
\text { TRIBUNAIS /São Paulo, } \\
1999.2^{\mathrm{a}} \text { tiragem da } 2^{\mathrm{a}} \text { edicão } \\
\text { revista de } 1997, \\
1^{\mathrm{a}} \text { edição, } 1996\end{array}$ & $\begin{array}{l}\text { Notas do autor nos } \\
\text { capítulos II, III e IV, } \\
\text { XIII, XXXII, XXXIV } \\
\text { Outras notas }\end{array}$ & UTET: Torino, 1911 & $\begin{array}{l}\text { Notas nos capítulos III, } \\
\text { XIII e XXXIV }\end{array}$ \\
\hline $\begin{array}{l}\text { 2. CD/São Paulo, } 2001 . \\
1^{\text {a }} \text { reimpressão da } 1^{\mathrm{a}} \text { edição } \\
\text { de } 2000\end{array}$ & Nenhum tipo de nota & Giuffrè: Milão, 1973 & $\begin{array}{l}\text { Notas nos capítulos II, } \\
\text { IV, VIII, XXXII, XXXV } \\
\text { e XXXVI }\end{array}$ \\
\hline $\begin{array}{l}\text { 3. HEMUS/Curitiba, } 2000 . \\
5^{\text {a }} \text { reimpressão da } 11^{\mathrm{a}} \text { edição }\end{array}$ & Notas do autor & - & - \\
\hline $\begin{array}{l}\text { 4. EDIPRO/São Paulo, } 2001 . \\
6^{\text {a }} \text { reimpressão da } 1^{\mathrm{a}} \text { edição } \\
\text { de } 1993\end{array}$ & $\begin{array}{l}\text { Notas do autor } \\
\text { Outras notas }\end{array}$ & - & 一 \\
\hline $\begin{array}{l}\text { 5. MARTIN CLARET/São } \\
\text { Paulo, } 2002\end{array}$ & $\begin{array}{l}\text { Notas do autor } \\
\text { Notas do editor }\end{array}$ & - & - \\
\hline 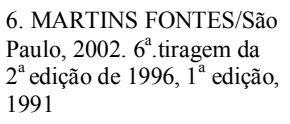 & $\begin{array}{l}\text { Notas nos capítulos III, } \\
\text { XIII e XXXIV } \\
\text { Notas do tradutor }\end{array}$ & $\begin{array}{l}\text { R.C.S. Libri - BUR: } \\
\text { Milão, } 2001 \\
\text { (após solicitação) }\end{array}$ & $\begin{array}{c}\text { Notas do autor nos } \\
\text { capítulos III, XIII e } \\
\text { XXXIV } \\
\text { Outras notas }\end{array}$ \\
\hline $\begin{array}{l}\text { 7. WVC Editora/São Paulo, } \\
2002\end{array}$ & Nenhum tipo de nota & - & 一 \\
\hline
\end{tabular}

\section{Das notas de rodapé}

Quanto às notas de rodapé, se, por um lado, tudo o que interrompe a leitura fluente do texto prejudica a sua legibilidade, por outro, essas notas podem constituir subsídios indispensáveis para a compreensão textual, como será analisado a seguir.

Verificando os dados da segunda coluna da Tabela 2, que assinalam a presença, ou não, de notas de rodapé no texto traduzido, é possivel observar que as editoras CD e WVC não incluem nenhuma nota. A editora Hemus apresenta as notas do autor. As outras quatro editoras, ou seja, Revista dos Tribunais, Edipro, Martin Claret e Martins Fontes propõem as notas do autor e outras notas como as do tradutor e/ou do editor. 
Passando à análise, quanto às editoras que não trazem nenhum tipo de nota, pode-se afirmar que elas estão desrespeitando o paratexto autoral que contém três notas de rodapé.

O fato de essas editoras omitirem as informações que contornam o texto, e que o autor julga importantes para a compreensão de seu discurso, possibilita afirmar que isso afeta o indice de legibilidade textual. Para citar apenas um exemplo, Beccaria esclarece na nota do capítulo XIII - Das testemunhas que, para os criminalistas, a credibilidade de uma testemunha é diretamente proporcional à gravidade do delito cometido, e que esse é um axioma "férreo e ditado pela mais cruel imbecilidade". ${ }^{1}$ As edições que omitem essa nota de rodapé autoral estarão privando o leitor de conhecer o ponto de vista do autor e, eventualmente, de entender outras observações contidas no texto relativas a essa nota.

A editora Hemus apresenta sete notas autorais e nenhuma nota editorial. Observa-se que as notas autorais não estão no rodapé da página, mas no final do livro, sob o título Notas de Beccaria, assinaladas com os números de chamada presentes no corpo do texto. Essas notas são precedidas, ainda, da resposta de Beccaria às observações que o frade dominicano Angelo Fachinei fez do seu trabalho e da reprodução da correspondência de Beccaria com o tradutor francês Morrelet.

Com isso, há 17 páginas separando o fim do texto beccariano das notas autorais, fato esse que dificulta sensivelmente sua consulta e desestimula o leitor a procurar as referidas notas, comprometendo a legibilidade.

Outra observação diz respeito à apresentação apenas das notas do autor, sem qualquer outro tipo de nota editorial ou do tradutor. Ao apresentar ao leitor o texto conforme o original, a editora preserva o formato do paratexto autoral e oferece ao leitor do texto traduzido os mesmos dados apresentados aos leitores do texto da língua de origem. Isso, contudo, não garante ao texto de chegada o mesmo nivel de legibilidade do texto de partida, pois o tradutor e o editor não podem ter certeza de que os leitores estrangeiros do texto traduzido detêm o mesmo conheci-

1 Cf. nota da editora Martins Fontes, p. 63. 
mento prévio dos leitores a quem Beccaria destinou sua obra. As notas do editor poderiam favorecer a legibilidade trazendo contribuições com relação, por exemplo, a aspectos históricos e políticos inerentes à obra de partida.

Sempre com relação às notas de rodapé e mais especificamente às notas do tradutor, foram consultadas diversas editoras para obter as diretrizes que elas dão a seus tradutores. A Editora Martins Fontes respondeu:

As notas são sempre traduzidas [sic] sendo eliminadas unicamente aquelas feitas especificamente para o público ao qual se dirigia originalmente o autor e que perdem o sentido na edição brasileira e adaptadas ou acrescentadas aquelas que trazem informações necessárias para o novo público de chegada. (Comunicação pessoal)

Quanto à orientação de acrescentar notas que trazem "informações necessárias para o novo público de chegada”, a editora em questão reforça o papel exercido pelas notas de rodapé, tendo em vista a necessidade de oferecer ao leitor maiores subsídios para a compreensão textual.

Com referência às quatro editoras da versão brasileira do tratado, que além das notas do autor propõem outras notas também, vale a pena fazer algumas observações.

A editora Revista dos Tribunais apresenta 34 notas de rodapé, das quais seis são atribuídas a Beccaria, sendo que o texto correspondente italiano da editora UTET 1911 traz apenas três notas autorais.

As notas, presentes na versão brasileira e ausentes no texto de partida, são as do capítulo II, IV e XXXII, sobre as quais seguem alguns esclarecimentos.

As observações atribuídas a Beccaria no capítulo II resumemse a uma explicitação de como o autor concebe as palavras direito e justiça. Esses esclarecimentos são um fator positivo com relação à legibilidade; no entanto, resta o fato de que essa nota não existe no texto de partida, não podendo ser atribuída ao autor.

A nota do capítulo III, por sua vez, remete o leitor à nota do capítulo sucessivo em que é dada uma explicação bastante ex- 
tensa das obrigações do cidadão para com a sociedade e desta para com o cidadão. Nesse texto, é citada parte da nota de Beccaria a qual realmente consta no capítulo III do texto de partida. Dessa nota autoral é retomado, no entanto, apenas um fragmento, englobado à explicitação da editora. E a editora atribui a Beccaria todo o texto da sua nota de rodapé. A nota editorial contribui para a inteligibilidade textual, mas a citação autoral não é completa e uma parte do texto é atribuída impropriamente ao autor.

Quanto à nota de rodapé do capítulo XXXII, que não existe no texto do original beccariano, a mesma esclarece um conceito apresentado pelo autor sobre o gozo do luxo. Conforme o autor, apenas uma minoria tira proveito do luxo, apesar de ter sido preparado por muitos agentes. Tanto no texto da língua de origem quanto no texto da língua de tradução, não há um bom indice de legibilidade desse trecho. A nota explicativa editorial é, portanto, oportuna com relação à legibilidade, mas não poderia ser atribuída ao autor.

Das observações acima, conclui-se que a editora Revista dos Tribunais preocupou-se bastante com o aspecto da legibilidade de seu texto, considerando o grande número de notas de rodapé além das notas do autor. Resta a perplexidade quanto à atribuição indevida de algumas notas ao autor e à ausência de explicitação das notas do tradutor.

A editora Edipro inclui, em sua tradução, 23 notas de rodapé - das quais sete são atribuídas a Beccaria; a editora Martin Claret traz 22 notas de rodapé das quais também sete são atribuídas ao autor e as restantes, explicitamente, ao editor. Como não foi identificado o texto de partida dessas traduções, fica impossivel fazer um cotejo com as notas autorais. Mas fica patente a preocupação dessas editoras com a compreensibilidade textual do leitor, tendo em vista o número de notas editoriais.

A editora Martins Fontes apresenta 15 notas do tradutor e mais cinco sem explicitar o enunciador.

Essa editora, nas suas Normas para Tradução, demonstra que quer evitar excesso de notas, pois sabe que tudo o que interrompe a leitura compromete a legibilidade. Dessa forma, não aceita notas explicativas para o público brasileiro em geral, pois 
os livros costumam ter público-alvo definido o qual, segundo a própria editora, deveria ser dotado das competências necessárias para a compreensão do texto que se propõe a ler. Tampouco a editora aceita esclarecer problemas de ordem lexical que podem ser resolvidos com uma consulta ao dicionário.

A editora, entretanto, reconhece ser necessário esclarecer ao público aquilo que o tradutor julga de dificil compreensão para o leitor estrangeiro daquela obra traduzida. As 15 notas do tradutor, na edição da Martins Fontes, atestam essa preocupação e vêm, de certa forma, exercer o mesmo papel elucidador das notas editoriais.

Quanto à presença das cinco notas sem explicitação da fonte enunciativa, o leitor pode entender que se trata de notas autorais ou editoriais. Apenas um cotejo com o texto da lingua de origem permitiu determinar que três dessas cinco notas são do autor e duas são observações editoriais.

Com relação às notas autorais, lembramos que elas fazem parte do texto, mesmo que o contornem apenas e devem ser tratadas como tais na versão traduzida. Diversamente, o leitor pode atribuir sua autoria ao editor - fato que pode acontecer ao leitor da edição da Martins Fontes - e, eventualmente, não levá-las em consideração como mereceriam.

Finalizando as reflexões acerca das notas de rodapé em texto traduzido, os dados levantados trazem à luz a necessidade de uma explicitação mais precisa da voz enunciativa. Com efeito, no texto da lingua de origem, basta especificar quais notas são as autorais e o leitor saberá, por exclusão, que as outras são do editor, ou vice-versa. Na tradução isso não basta, pois há, também, a voz do tradutor.

A seguir, resumidos na Tabela 3, serão tratados outros aspectos do paratexto, tais como a presença, nos textos traduzidos, da ilustração e a da tradução da epígrafe. 


\section{Tabela 3}

Presença da ilustração e da epígrafe no texto da língua de tradução de Dos Delitos e das Penas, de Cesare Beccaria.

\begin{tabular}{|c|c|c|c|}
\hline $\begin{array}{c}\text { Editora do texto da Língua } \\
\text { de tradução }\end{array}$ & $\begin{array}{c}\text { ILUSTRAÇÃO } \\
\text { na capa do texto } \\
\text { traduzido e no da língua } \\
\text { de origem }\end{array}$ & $\begin{array}{c}\text { EPÍGRAFE } \\
\text { no texto traduzido }\end{array}$ & $\begin{array}{c}\text { EPÍGRAFE } \\
\text { no texto da língua de } \\
\text { origem }\end{array}$ \\
\hline $\begin{array}{l}\text { 1. REVISTA DOS } \\
\text { TRIBUNAIS/São Paulo, } \\
1999.2^{\mathrm{a}} \text { tiragem da } 2^{\mathrm{a}} \text { edicão } \\
\text { revista de } 1997,1^{\mathrm{a}} \text { ed. } 1996\end{array}$ & $\begin{array}{l}\text { Presente / LT } \\
\text { Ausente / LO }\end{array}$ & Em latim, com tradução & $\begin{array}{c}\text { UTET: Torino, } 1911 \\
\text { Em latim, sem tradução }\end{array}$ \\
\hline $\begin{array}{l}\text { 2. CD, São Paulo, } 2001 . \\
1^{\mathrm{a}} \text { reimpressão da } 1^{\mathrm{a}} \text { edição de } \\
2000\end{array}$ & $\begin{array}{l}\text { Presente /LT } \\
\text { Presente /LO }\end{array}$ & Em latim, sem tradução & $\begin{array}{c}\text { GIUFFRÈ: } 1973 \\
\text { Em latim, sem tradução }\end{array}$ \\
\hline $\begin{array}{l}\text { 3. HEMUS, Curitiba, } 2000 . \\
5^{\text {a }} \text { reimpressão da } 11^{\mathrm{a}} \text { edição }\end{array}$ & Presente / LT & Ausente & 一 \\
\hline 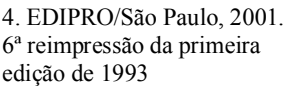 & Ausente / LT & Ausente & - \\
\hline $\begin{array}{l}\text { 5. MARTIN CLARET/São } \\
\text { Paulo, } 2002\end{array}$ & $\begin{array}{c}\text { Presente / LT } \\
-\end{array}$ & Ausente & - \\
\hline 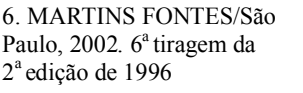 & $\begin{array}{l}\text { Presente /LT } \\
\text { Presente / LO }\end{array}$ & Em latim, com tradução & $\begin{array}{c}\text { R.C.S. Libri - BUR: } \\
\text { Milão, } 2001 \\
\text { Em latim, com tradução }\end{array}$ \\
\hline $\begin{array}{l}\text { 7. WVC Editora/São Paulo, } \\
2002\end{array}$ & $\begin{array}{c}\text { Presente / LT } \\
-\end{array}$ & Em latim, sem tradução & - \\
\hline
\end{tabular}

\section{Da ilustração}

Pela Tabela 3, observa-se a presença da ilustração em seis das sete edições brasileiras da obra Dos delitos e das penas.

A ilustração, apesar de não ser um dado verbal, é um instrumento de geração de sentido muito eficiente. Com efeito, o recurso ao ícone remonta à forma primordial de o homem registrar sua história.

Na capa de um livro, a ilustração pode retirar a ambigüidade gerada, por exemplo, pelo título, cuja apreensão seria mais complicada se o leitor fizesse uma análise lingüística stricto sensu, especialmente naqueles casos em que se requerem do leitor da obra traduzida conhecimentos prévios que ele não detém. 
Essas reflexões levam-nos a considerar que a presença da ilustração, no paratexto de uma obra, eleva o nível de sua intelegibilidade.

\section{Da epigrafe}

Com relação à epígrafe, é necessário esclarecer que na obra Dos delitos e das penas, ela consiste na retomada de um aforismo de Francis Bacon, filósofo inglês. Por meio dela, Beccaria antecipa ao leitor qual é sua expectativa quanto à recepção do Tratado. A máxima de Bacon é citada em latim, antes da Introdução, e diz: "Em todas as coisas, e especialmente nas mais dificeis, não devemos esperar semear e colher ao mesmo tempo, mas é necessária uma lenta preparação para que elas amadureçam gradativamente." 2

A máxima de Bacon remete a uma regra universal da natureza - a de que semear e colher não podem ser atos simultâneos. Beccaria ilustra essa regra e a aplica a seu caso particular, argumentando, assim, que a demora na colheita, isto é, na aceitação pela sociedade de suas idéias - revolucionárias naquele momento histórico - deve ser atribuída à necessidade de amadurecimento sobre o assunto. Considerando o prestígio de que goza Bacon, o jurista italiano Beccaria, ao compartilhar das idéias do filósofo inglês, reforça a validade das idéias apresentadas. Nesse trecho, o autor lança mão de duas estratégias argumentativas - a ilustração e o argumento de autoridade - e, ao argumentar por antecipação, evita que desqualifiquem suas idéias.

Passando à verificação da presença da epígrafe no texto traduzido e à análise do tratamento que lhe é conferido pelas editoras, a Tabela 3 mostra que, das sete edições brasileiras, três omitem a citação da epígrafe. Dentre as quatro edições que incluem a epígrafe em seu texto, duas a propõem em latim, sem tradução, e duas em latim, com tradução.

Observa-se, além disso, que das três edições italianas reconhecidas como ponto de partida para a tradução em portu-

2 Ed. Martins Fontes, 2002, p. 31. 
guês, a editora milanesa R.C.S. Libri (BUR, 2001) recicla o paratexto autoral, acrescentando ao aforismo do filósofo inglês a tradução para o italiano. Lembramos que a obra beccariana de 1766, na qual a editora declara basear sua edição, cita o aforismo apenas em latim, assim como o fazem as editoras UTET e Giuffrè.

Inicialmente, entende-se que a ausência da epígrafe, no texto traduzido, é uma forma de transgressão com referência ao paratexto autoral. Além disso, tendo em vista que a epígrafe dá pistas de leitura, que geram predições e expectativas, percebese que sua ausência dificulta a compreensão textual plena, pois priva o leitor de estabelecer referidas predições.

Por sua vez, a presença da epígrafe sem tradução gera, do mesmo modo, problemas de leitura, pois não há garantias quanto ao conhecimento da língua latina por parte do leitor que, ao não compreender o texto do aforismo, não recupera as informações nele contidas.

Avalia-se que, em ambos os casos, os textos apresentam problemas de legibilidade, visto que dificultam a extração de informações que possam recuperar, tanto quanto possivel, as informações do original.

Apenas nas duas edições com a epígrafe em latim traduzida é que não há problemas de legibilidade. Essa seria, portanto, a opção mais adequada para a versão destinada ao leitor brasileiro, em geral, de hoje.

Esse ponto de vista se confirma, por exemplo, ao ponderarmos sobre a atitude tomada pela editora italiana R.C.S. Libri. Se, por um lado, a sua postura transgride o paratexto autoral ao apresentar a tradução da epígrafe do latim para o italiano por outro, prioriza a legibilidade.

\section{De outros dados do paratexto}

Observa-se que a editora Revista dos Tribunais acrescenta, ainda, uma Nota dos tradutores à primeira edição. Abaixo da epígrafe aparece uma citação em alemão (sem indicar o autor), assim traduzida no pé de página: "Tão fiel quanto possivel, tão livre quanto necessário." Infere-se que se trata de uma observa- 
ção editorial relativa ao resultado da versão brasileira da obra, em função das modalidades tradutórias adotadas.

Ainda, no tocante ao paratexto editorial, acrescenta-se que as editoras CD, Revista dos Tribunais e Martins Fontes redigiram, de forma autônoma, o prefácio, a apresentação do autor e de sua obra, isto é, não se basearam no prefácio ou na cronologia dos respectivos textos-fonte. Essa postura acentua a presença da editora que, junto com o tradutor, assume o papel de mediadora entre o autor e o leitor.

\section{Considerações finais}

As considerações seguintes tencionam resumir os principais pontos abordados neste trabalho. A análise de aspectos paratextuais de três edições do texto de partida e sete edições do texto de chegada do tratado Dos delitos e das penas evidenciou que os fragmentos verbais, que apenas contornam o texto, assumem um papel considerável para a compreensão.

Ficou provado, ainda, que todos os aspectos textuais, até os não-lingüísticos, como a ilustração na capa do livro traduzido, desempenham um papel determinante para a inteligibilidade. A reprodução das ilustrações é desejável, pois pode retirar a ambigüidade gerada, por exemplo, pelo título, cuja apreensão seria mais complicada se o leitor fizesse uma análise lingüística stricto sensu, especialmente naqueles casos em que se requerem do leitor da obra traduzida conhecimentos prévios que ele não possui.

Verificamos que a epígrafe dá pistas de leitura e gera expectativas; não traduzi-la acarreta a perda de dados autorais relevantes, pois ela concentra um alto poder de argumentação.

Comprovamos, outrossim, que especificar o enunciador das notas de rodapé é fundamental para o reconhecimento da voz enunciativa, tendo em vista a polifonia que caracteriza o texto traduzido. Com relação às notas de rodapé editoriais e do tradutor, elas podem explicitar implícitos de dificil apreensão para o leitor do texto traduzido e, igualmente, explicitar subentendidos presentes no texto da língua de partida, cujos pressupostos não são compartilhados pelos leitores do texto da lingua de chegada. 
Por sua vez, a inclusão, na edição traduzida, de textos elucidativos sobre a tradução, a obra e seu autor é um recurso que favorece a apreensão discursiva. Constitui-se, ainda, numa postura que evidencia a presença da editora e do tradutor que, juntos, assumem de forma visível o papel de mediadores culturais.

Finalizando, parece adequado reconhecer as múltiplas funções do paratexto em geral e, especialmente, do paratexto da obra traduzida. Ele representa, pois, um dentre os diversos fatores que incidem nos niveis de legibilidade e coerência textual, cuja presença garante a manutenção argumentativa.

Resta ainda auspiciar que tradutores, revisores e editores zelem pelo paratexto da mesma forma como o fazem com o corpo do texto.

\section{Referências bibliográficas}

BASTIANETTO, P. C. (2004) Legibilidade e argumentação em textos traduzidos - estudo de sete traduções da obra Dos delitos e das penas, de Cesare Beccaria. 2004. 225 f. Tese (Doutorado em Letras) - Faculdade de Filosofia, Letras e Ciências Humanas, USP, São Paulo (Mimeografado).

BECCARIA, C. (2002) Dos delitos e das penas. Tradução de Lucia Guidicini e Alessandro Berti Contessa. São Paulo: Martins Fontes. 139 p. Original italiano.

. (2001) Dei delitti e delle pene. Milano: BUR.

FULGÊNCIO, L.; LIBERATO, Y. (2000) Como facilitar a leitura. São Paulo: Contexto. 100 p. $1^{\text {a }}$ ed. 1992. (Repensando a Língua Portuguesa). MAINGUENEAU, D. (2001) Análise de textos de comunicação. São Paulo: Cortez.

. (2000) Termos-chave da análise do discurso. Belo Horizonte: Editora UFMG. 